\title{
AHP IN CHINA'S COAL INDUSTRY: APPLICATION AND RESEARCH
}

\author{
Zhou Dequn Jing Hongwen \\ China University of Mining and Technology, Xuzhou, 221008, P.R.China \\ Tian Fuling \\ Qiwu Coal Mine, Shandong, 277606, P.P.China
}

\begin{abstract}
Since AHP was introduced in China in 1982, different management levels have thought highly of it. The application and research of AHP has achieved successes in the coal industry. In this paper, we shall study some important positive results related to the AHP method and conclude with some main application areas in the coal industry. Further, some features of AHP and several issues about the effective application of AHP will be discussed.
\end{abstract}

\section{Introduction}

As a systematic analysis method, AHP ( Saaty, 1980) can change the decision process of a complicated problem into a structure model And a simple mathematics calculation. By using the AHP method, people can make a judgment and analysis on the level of sub- problems that are easier than original complicated ones and finally find solutions to them. To ensure consistency of the judgment process, AHP also provides an inspecting method that makes it possible to make amendments at any time. AHP is an effective method that synthesizes subjective judgment and features both qualitative and quantitative analyses.

Since AHP was introduced to China in 1982, it has been highly thought of at different decision levels. Great progress has been made in the application and research of AHP in the coal industry. We shall study some important positive results related to this method and concluded some main application areas. Some features of AHP in solving practical problems are also discussed in this paper.

As a new decision method, AHP is now in a stage of improvement. Considering research achievements of some scholars in coal industry, we discuss several issues about the effective applications of AHP.

\section{Applications of AHP in China's coal industry}

A famous case was introduced by Wang (1984) in which the Institute of System engineering, Xi'an Jiaotong University made an overall development plan for the Shanxi coalbase using AHP. Their hierarchy model included total objective, strategy objective, developing strategy, and limited factors and alternatives. The conclusions are to take the measure of collecting capital, support local government in policy, improve transportation conditions, broaden better sources of income and reduce expenditures. Their proposals have been accepted by Shanxi provincial government. Besides, they also studied the coordination and development proportion of three different kinds of mines ( state-owned ones, local-owned ones, township or village- owned ones) and formed three developing alternatives (see Wang, 1988 ) . 
Zhang ( 1988 ) applied AHP to the planning of a mining area. Considering both the present state and long- term development of Pingdingshan Mining Administration, the Dept. of Mining Engineering of China University of Mining and Technology (CUMT) designed and analyzed five production alternatives, and finally selected a optimum one by using three criteria, i.e., maximization of output, maximization of profit and comprehensive consideration of the above two.

Jiang ( 1987 ) solved a capital assignment problem by using AHP. In his model, he proposed four criteria, i.e., saving investment, increasing profit, creating new jobs and improving workers' welfare. Seven strategies of mine development were evaluated. His main conclusions provide the mine with a basis to use capital rationally.

Zhao ( 1988 ) researched mine development with the aid of AHP. He selected investment, project time, annual production and project cost as criteria of evaluating four alternatives ( cage vertical shaft, skip vertical shaft, car string winding inclined shaft, belt conveyor inclined shaft ) and obtained their priority weight.

Wang ( 1994 ) evaluated three mining alternatives. In the standard level, there are five reliable factors to be considered ( ventilation system, production increase, replacement of tunneling operation face, obtaining profit, transportation system). Using AHP, an optimum alternative was selected and evaluated in detail with the consideration of the economy and technology.

Xie ( 1992 ) used AHP to study technical reconstruction of a coal mine. An alternative system with mixed series-parallel structure was also evaluated.

In order to comprehensively evaluate the state of coal resource to be suitable for surface mining and make an optimum decision in the development of order, Zhang (1994) designed an evaluating index system and constructed a model. Starting with a quantified evaluation of the quantity and quality of coal reserves, mining and environmental conditions, and the weight of each index was calculated with AHP. This lead to a decision on the optimum exploitation order of surface coal fields.

Liu ( 1994 ) constructed a structural model, consisting of 4 aspects and 40 factors that affect an enterprise's' competitive power. With the aid of this model, some problems can be found along with measures to solve a problem.

In addition to the above cases, AHP was also effectively used in other fields $(6,7,8,9,13,16)$ such as managing safety, selecting operation method, judging input and output of a new mine, choosing policy to reduce energy expenditure, classifying mine areas, separating raw coal cost, selecting cadres, etc. We believe that AHP will be used more in the Chinese coal industry.

Why does this method have such a great attraction? What factors attract people to try AHP? The following is the answer from practicers and researchers.

AHP can help me put my thinking in order. It is suitable for complicated decision problems with the feature of multiobject, multicriteria, multialternative and multistage.

.Compared with other methods, AHP needs few data but requires much more thinking to the problem about its structure, its factors and its inner connection.

Decision makers can directly participate in the decision analysis process because constructing the judgment matrix is relatively easy.

.Analysis members can draw forth the judgment of decision makers with the aid of the judgment matrix. Then obtain conclusions of a complicated problem that conforms to the decision-maker's thoughts. 
AHP is especially suitable for solving unstructured and semi-structured problems such as planning of mining areas.

\section{How to use AHP effectively: review and some discussions}

Including the wide application of AHP in China's coal industry, the research about AHP has also made further achievements. Below, we will refer to some achievements of researchers in the coal industry and discuss a few issues about how to use AHP effectively.

\section{How to imbibe group knowledge?}

It is obvious that objects, standards, measures and alternatives can not form automatically. AHP can only provide us with a kind of method, with which, we can organize and quantitatively analyze the problem. However selection of the basic elements in the hierarchy model depends on our knowledge and understanding of problems. Most of these problems are comprehensive and can not be solved by one individual. Therefore, it is very important to have experts of different fields to participate in constructing the model and evaluating it. Zhang (1994) applied group AHP theory under the circumstance of full and uncompleted information to study the planning of Pingdingshan mining areas and determined optimum reconstructing alternatives. With this knowledge, a new method about group decision was advanced.

\section{How to construct a judgment matrix and how to obtain a better weight?}

AHP starts with problem analysis and results in weight calculation. In this process, The key is to construct a judgment matrix. In the last few parts, how to improve the constructing method and how to raise the consistency of evaluation has been a focal point of study. Some researchers in the coal industry have made such achievements.

$\mathrm{Ru}$ ( 1990 ) improved the traditional method of constructing the judgment matrix. His conclusion was quoted by many researchers. He also systematically studied artificial error ( $\mathrm{Ru}, 1995$,) expounded the reasons of artificial error in system error and offered two effective methods for eliminating artificial error in evaluation.

In order to overcome the difficulties in constructing the judgment matrix, Yang $(.1994,1995)$ advised on how to construct mixed group judgment matrix in which both quantity factors and quality factors exist. He put forward an indirect method to construct the judgment matrix in view of different factors.

In general, we construct the judgment matrix on the basis of comparing importance between factors, but ignore the interplay between factors. Zhou ( 1992) advanced AHP with a cross support analysis and used it in analyzing and forecasting of mine efficiency.

\section{How to increase decision satisfactivity?}

From the view of the AHP application, there exists a trend that the conclusion of a judgment matrix is excessively conceived but the understanding of the problem itself is ignored. We called it "attend to trifles to the neglect of essentials." In fact, the judgment matrix is only a result of subjective judgment. Acceptable consistency ratio can not ensure reliability of a conclusion, as it only shows good consistency in judgment from beginning to end. To improve reliability of the conclusion, it is necessary to which each result according to an experts' authority and reduce subjective error of individual judgment to little as possible. (Zhou, 1992)

\section{How to consider fuzzy judgment?}


With the wide application of AHP in the coal industry, some problems have become more complicated. Therefore it is important to know how to deal with a fuzzy judgment.. Xu ( 1988 ) puts forward a method to construct a fuzzy judgment matrix and order the factors by the means of statistics.

\section{How to combine AHP with other methods?}

AHP needs less information than other methods. To a great extent, the structuring of the judgment matrix is subjective. Some cases show that decision quality would be improved if AHP were combined with other methods such as the Delphi method, Fuzzy set, ISM, DEA, DSS and so on. For example, Song (1986) studied a planning method of mining areas by combining AHP with the Delphi method. Wei ( 1993 ) applied fuzzy set theory and AHP to evaluate economic effects of coal enterprises. Zhou ( 1994 ) recommends a grey system model with dynamic AHP and explored alternatives of investment assignment.

\section{Conclusion}

As a scientific decision method, AHP plays an important role in China's coal industry. AHP faces many difficulties in solving economic and management problems. The main obstacles do not come from AHP theory itself, but from traditional and habitual ways of thinking. To popularize this new method, there is a lot to do. In China, coal shares about $75 \%$ of the total energy production. China's energy industry is on the way to market economy from plan economy. With this progress, it is hard for us to avoid various complicated problems-economical, social and environmental. To help solve some of these problems, more effective methods might be combining qualitative with quantitative. We believe that AHP will be understood and applied by more people.

\section{References}

Jiang, G.A, (1987) "Application of AHP in Developing Nantun Coal mine," The Journal of China Coal Society, Vol.12 No.2, 13-19. (in Chinese).

Liu, J, (1994) "Optimization of Enterprise Quality By Applying AHP Method," The Journal of China Coal Society, Vol.19 No.4, 403-402. (in Chinese).

$\mathrm{Ru}, \mathrm{Z}$. H, (1990) "A Study of Constructing Method of Judgment Matrix in Hierarchical Analysis," System Engineering, Vol.8 No.1, 43-44. (in Chinese).

to

Ru, Z. H, A (1995) "Study of The Artificial Error Problem in The AHP, "Journal of Shandong Mining Institute, Vol.14 No.2, 154-157. (in Chinese).

Saaty, T. L, (1980) “The Analytic Hierarchy Process," McGraw Hill, Inc.

Song, Y. F, (1986) "Application of AHP and Delphi Method in Long- term Planning of Mining Areas," Designing of Coalmine, No.9, 12-16. (in Chinese).

Song, Z.X, (1993) "Application of AHP in Prevention and Control of Coal Dust Explosion," Coal engineer, April, No.2, 27-34. (in Chinese).

Song, Y.F, (1993) "Using AHP to Select Construction Way of Erect Pit," Coal economic Research, Nov, , 
No. 11, 3y-44. (in Cininese).

Tu, S. H, (1993) "The Application of AHP in Selecting Mining Method," Coalmine Technique, Vol.13 No.2, 23-25. (in Chinese).

Wang, Y. L, (1984) "Preliminary Exploration to the Strategy Decision of Planning Shanxi Coal Areas," System Engineering, Vol.2 No.2, 31-38. (in Chinese).

Wang, Y. L, (1988) "A Study of Coordination developing proportion of three kinds of mines ( stateowned mines, local-owned mines, township --village mines, " Collections of System Engineering Cases, China Science Press, (in Chinese).

Wang, L. Q, (1994) "Optimum Mining Alternatives by The Use of AHP," Coalmine Technique, Vol.14 No.1, 27-32. (in Chinese).

Wei, M.S, (1993) "The Comprehensive Evaluation Method and Its Application on The Economic Effects of Coal Enterprise," System Engineering -Theory \& Practice, Vol.13 No.2, 65-74. (in Chinese).

Xian, C. E, (1992) "Determining Restructuring Alternatives With The Method of AHP, " Shanxi Coal, March No.5, 31-37. (in Chinese).

$\mathrm{Xu}, \mathrm{R} . \mathrm{L}$, (1988) "Constructing of Fuzzy Judgment Matrix and Ordering in AHP, "System Engineering, Vol.6 No.5, 52-61. (in Chinese).

Yang, D, (1987) "A Trying of Using AHP to Compare Investment Benefit of Two New Coal Mines," Coal economic Research, November, No.11, 31-34. (in Chinese).

Yang, Y. Q, (1994) "The Construction and Application of Judgment Matrix of the Group-AHP Method with Mixed Factors," System Engineering, Vol.12 No.3, 68-73. (in Chinese).

Yang, Y. Q, (1994) "A Policy-functioned Analytic Hierarchy Process, “ Journal of Huainan Mining Institute, Vol.15, No.2, 66-72. (in Chinese).

Zao, H. C, (1986) Analytic Hierarchy Process: A New Decision Method, China Science Press, 52-53 . (in Chinese).

Zhang, X. C, (1988) The Planning of Pingdingshan Mining Area, CUMT, (in Chinese).

Zharig, R. X; (1995) "Determination of the 'Index System and Weights for the Comprehensive Evaluation of Surface Coalfields," Journal of Guizhou Institute of Technology, Vol.24 No.1, 32-38.'(in Chinese).

Zhang, Y. X; (1994) "A Conflict Coordination Method in Group Decision and Its Application in Coal' Mining," Coalmine Technique, February No.1 35-37. (in Chinese).

Zhou, D. Q, (1992) "CSAHP Model for Analysis and Forecast of Mine Efficiency," Journal of.East China Institute of Technology, December, No.6 10-14. (in Chinese).

Zhou, D. Q, (1992) "A Study of Optimum Evaluation Method of Enterprise Managerial Achievement;" Statistics \& Management, December , No.4, .20-22. (in Chinese).

Zhou, D. Q, (1994) "A Procedure of Dynamic Ordering Via.Grey System," The Journal of Grey System, Vol.6 No.3, 167-174. 